\title{
Financial Stress Among Latino Adults in California During COVID-19
}

\author{
Luisa Blanco $^{1} \cdot$ Vanessa Cruz $^{1} \cdot$ Deja Frederick $^{1} \cdot$ Susie Herrera ${ }^{1}$
}

Received: 16 March 2021 / Revised: 11 July 2021 / Accepted: 20 July 2021 / Published online: 2 August 2021

(c) The Author(s), under exclusive licence to Springer Nature Switzerland AG 2021

\begin{abstract}
We study the impact of COVID-19 on stress, and especially on financial stress, among Latino adults in California. We take a mixed methods approach and rely on quantitative and qualitative data for our analysis. We recruited 84 lowand moderate-income (LMI) Latino adults in California through the Understanding America Study (UAS) Internet Panel who also participated in the Mobile Financial Diary (MFD) project, which took place during 2018 - 2019. We analyze data about personal experiences during COVID-19 in October 2020 and compare this to data collected during the period from August to October 2018. Our study portrays the experiences of California Latino adults who were predominantly born in the USA and are likely to be working and speak English. We also observe that a large percentage of our participants had health insurance and relatively high levels of educational attainment. We find contradictory results from our quantitative measures, where one of our indicators of financial behavior and wellbeing showed a significant increase (Financial Health Score), and the other (Financial Well-Being Scale) showed a significant decrease during COVID-19. Anxiety (GAD-7) and depression (PHQ) measures show no significant changes during COVID-19 in comparison to 2018. Nonetheless, our qualitative data analysis shows that many of our participants were experiencing major stressors during the pandemic associated with labor market experiences and family circumstances. In our qualitative data analysis, we also observe that women seemed to have been affected the most by the pandemic.
\end{abstract}

Keywords Mental health $\cdot$ Financial stress $\cdot$ Financial well-being $\cdot$ COVID-19 $\cdot$ Latinos

\section{Introduction}

Data has shown that there are important racial, ethnic, and gender disparities during the pandemic (Pastor and Segura 2020; Zamarro and Prados 2021). The negative impacts of COVID-19 on health and economic outcomes have been felt disproportionately among communities of color (Pastor and Segura 2020). As a result, pandemic-related stress is likely to be more prevalent among African American and Latino

Luisa Blanco

lblanco@pepperdine.edu

Vanessa Cruz

vanessa.cruz@pepperdine.edu

Deja Frederick

deja.frederick@pepperdine.edu

Susie Herrera

susie.herrera@pepperdine.edu

1 Pepperdine University, 24255 Pacific Coast Highway, Malibu, CA 90265, USA communities than among Whites, with important implications for mental health (Grooms et al. 2020).

We study the impact of COVID-19 on stress, and especially financial stress, among Latino adults in California. We took a mixed methods approach and rely on quantitative and qualitative data for our analysis. We recruited a convenience sample of low- and moderate-income (LMI) Latino adults in California through the Understanding America Study (UAS) Internet Panel who also participated in the Mobile Financial Diary (MFD) project. For the MFD project, we collected data in 2018-2019 during a period of 8 months among a convenience sample of LMI Latinos in California (sample stratified by income and age) who were part of the UAS. The main goal of the MFD project data collection was to better understand the relationship between financial well-being and stress among Latinos. We invited all participants who were part of the MFD to complete our survey about the impact of COVID-19 on finances and stress in November 2020. We had 84 of 134 MFD participants complete our survey (63\% response rate). 
We report findings about personal experiences during COVID-19 in October 2020 and compared this to data collected from August to October in 2018. Our study portrays the experiences of California Latino adults who were predominantly born in the USA and are likely to be working and speak English. We also observe that a large percentage of our participants had health insurance and relatively high levels of educational attainment. We find contradictory results from our quantitative measures, where one of our indicators of financial behavior and well-being showed a significant increase (Financial Health Score), and the other (Financial Well-Being Scale) showed a significant decrease during COVID-19. Anxiety (GAD-7) and depression (PHQ) measures show no significant changes during COVID-19 in comparison to 2018. Nonetheless, our qualitative data analysis shows that our participants were experiencing major stressors during the pandemic associated with labor market experiences and family circumstances. In our qualitative data analysis we also observe that women seemed to have been affected the most by the pandemic.

Our paper is organized as follows. We provide a background section where we discuss public data and previous work on racial, ethnic, and gender disparities during COVID-19. In this section, we also discuss Latinos' experiences in California during COVID-19 to provide a context for the reader who might not be familiar with the policies and environment in this state during the pandemic. Then, we discuss in the methodology section our data, measures, and methods. We discuss the findings of our quantitative and qualitative data analysis in the results section. We end with a discussion of our findings and a conclusion.

\section{Background}

\section{Racial, Ethnic, and Gender Disparities During COVID-19}

African Americans, Latinos, and women have fared worse than other groups during the COVID-19 pandemic in relation to health and labor market outcomes. In particular, African American and Latino populations have had a higher COVID-19 mortality rate and greater susceptibility to the virus. People of color are at disadvantage during the pandemic because they are not only more likely to have an essential job and a higher predisposition to health conditions, but also to live in larger households, have lower levels of savings, and be less likely to have health insurance (Andrasfay and Goldman 2020; Azcue et al. 2020; Dubay et al. 2020).

Relative to Whites, American Indian/Alaska Native individuals, and Latinos and African Americans are 1.7 times, 1.3 times, and 1.1 times more likely to contract COVID-19, respectively (Center for Disease Control 2021). ${ }^{1}$ COVID19 has reduced life expectancy for African Americans by 2.10 years and for Latinos by 3.05 years (Andrasfay and Goldman 2020). By contrast, COVID-19 has decreased life expectancy for Whites by 0.68 years (Andrasfay and Goldman 2020).

COVID-19 has also increased racial and ethnic disparities in the labor market. From February 2020 to February 2021, data from the US Bureau of Labor Statistics (BLS) show greater increases in unemployment for minorities. During this time, the unemployment rate for Whites increased by 2.6 percentage points, compared to the increase of 3.9 percentage points for African Americans and 4.1 percentage points for Latinos. Similarly, while the labor force participation rates (seasonally adjusted) during that time decreased 1.8 percentage points for Whites, it decreased by 3.0 and 2.6 percentage points for African Americans and Latinos, respectively. ${ }^{2}$

People of color and those with low income were less likely to work remotely, but more likely to have experienced a decrease in spending for food, used savings or greater credit card debt, and put off major purchases during the pandemic (Acs and Karpman 2020; Gonzalez et al. 2020; Karpman et al. 2020). While 61\% of Latinos in April 2020 stated that someone in their household or themselves had lost wages or a job, only $38 \%$ of White adults reported the same (Lopez et al. 2020). Furthermore, $70 \%$ of Latino adults reported that they did not have funds to cover emergency expenses for 3 months, and $44 \%$ reported that they could pay their bills or only make partial payments of their bills (Lopez et al. 2020).

Another study found that in May 2020, 43\% of families reported a job or income loss due to the pandemic, and the losses were higher for low-income families and Latinos (Acs and Karpman 2020). Acs and Karpman (2020) found that $55 \%$ of Latino adults reported an economic loss, and those with non-citizen members were $14 \%$ more likely to experience economic losses than families whose members were all citizens (Acs and Karpman 2020). Gonzalez et al. (2020) found that among Latino families with non-citizens, $50 \%$ used savings or increased debt on their credit cards, $42 \%$ experienced food insecurity, $25 \%$ could not meet needs for medical care, $20 \%$ were unable to pay utilities (gas, oil, electricity), and $18 \%$ were unable to pay the entire amount for rent.

The negative impacts of COVID-19 have important implications for the mental health of people of color, particularly in relation to stress. During the pandemic, individuals experienced four types of situational anxiety: health-related,

\footnotetext{
${ }^{1}$ Statistics retrieved from CDC website on March 12 of 2021.

2 Statistics retrieved from the BLS website on March 12 of 2021.
} 
economic-related, daily routine change, and social isolation (Bareket-Bojmel et al. 2020). Health-related anxiety in the context of COVID-19 is connected to experiencing excessive fear of getting COVID-19. Social isolation is related to feelings of loneliness that could lead to increased stress and other mental health disorders such as depression. During COVID-19, almost everyone experienced significant changes to daily routines related to work, school, and family, which resulted in stress. Bareket-Bojmel et al. (2020) found that economic-related and health-related anxiety were about equal and exceeded anxiety resulting from social isolation and daily routine change (Bareket-Bojmel et al. 2020). An American Psychological Association (APA 2020a) survey found that $63 \%$ of US households identified finances as a major stressor during the pandemic, which is higher than the $46 \%$ that was observed before the pandemic in 2019 . This survey also showed that $73 \%$ of households with an income less than $\$ 50,000$ and $59 \%$ of households with income greater than $\$ 50,000$ identify finances as a significant stressor during the pandemic (APA 2020a).

Communities of color are likely to experience higher levels of health- and economic-related stress than Whites. In a study about mental health outcomes during the pandemic, Grooms et al. (2020) found that essential healthcare workers showed higher levels of stress, while African Americans showed higher levels of anxiety, and Latinos showed higher levels of depression relative to other groups. Grooms et al. (2020) also found that depression and anxiety were higher among African American and Latino essential workers outside healthcare. Another study showed that Latino parents 18 to 29 years old and those with income levels of no more than $\$ 25,000$ had among the highest levels of economic stress in comparison to other groups (Vargas and Sanchez 2020). Such stress has led Latinos to engage in concerning behaviors such as using pay-day loans and postponing educational and health-related expenses (Vargas and Sanchez 2020).

Gender disparities are also prevalent during COVID-19. Zamarro and Prados (2021) found that mothers have been more likely than fathers to become the sole providers for their children. They also found that mothers experienced much higher levels of psychological stress than women who did not have younger children within their household. They did not find a significant difference in psychological distress between fathers and men without younger children. Zamarro and Prados (2021) also showed that many women have responded to the increased demands of childcare during the pandemic by leaving the labor force or working fewer hours.

Labor market challenges have been greater for women during the pandemic and especially for Latinas. Blanco et al. (2020) found that Latinas have experienced the highest rates of unemployment during the pandemic. Latinas between the ages of 40 and 44 were more likely than Blacks or Whites to be mothers of three or more children and more likely to be negatively impacted by the loss of childcare and the closures of schools during the pandemic. Latinas also experienced greater increases in unemployment, especially through job separation (Blanco et al. 2020).

\section{Latino Adults Experiences in California During COVID-19}

California's economy has been greatly affected by the pandemic due to its high COVID-19 infection and mortality rates. According to data from the New York Times (2021), as of July 9 of 2021, in Alabama, there were 11,277 COVID19 cases per 100,000 residents and 232 deaths from COVID19 per 100,000 residents. For New York, there were 10,879 COVID-19 cases per 100,000 and 273 deaths per 100,000 rates. California's neighboring state Oregon had COVID19 cases and death rates of 4980 and 67, respectively. In comparison, California had 9693 COVID-19 cases and 160 deaths per 100,000 residents (The New York Times 2021). The governor declared a state of emergency in March 2020. With government-mandated closures, California residents were asked to stop all non-essential travel and work from home. Schools throughout the state also closed. Non-essential businesses were forced to close, leaving many workers without a job or a stable income. Many businesses that were permitted to remain open had trouble adjusting to the quickly changing policies and regulations coming from the federal, state, and local governments.

The first stay-at-home order, specifically a public health and executive order, was issued on March 19, 2020. This instructed people to remain at home, with exceptions for essential workers and essential shopping (COVID-19.CA 2021). By November 21, 2020, a "Limited Stay at Home Order" instituted a requirement that purple tier counties with more than $8 \%$ positive tests stay at home between 10:00 pm and 5:00 am. Purple tier counties consist of a county where the virus is widespread, specifically having more than seven cases per 100, 000 people (Tadayon 2021). A subsequently regional stay-at-home order forbidding any private gatherings was issued on December 3, 2020, in response to intensive care unit availability dropping below 15\% (COVID-19. CA 2021).

Racial and ethnic disparities have become more visible in California during the pandemic, with the Latino community being affected the most. State government data show that Latinos are more likely than other groups to contract COVID-19 and die from it. ${ }^{3}$ The most recent statistics, as of March 2021 when this analysis was conducted, indicated that Latinos have represented 56\% of all COVID-19

\footnotetext{
${ }_{3}$ COVID-19 data discussed here was accessed from CA.gov website on March 12 of 2021.
} 


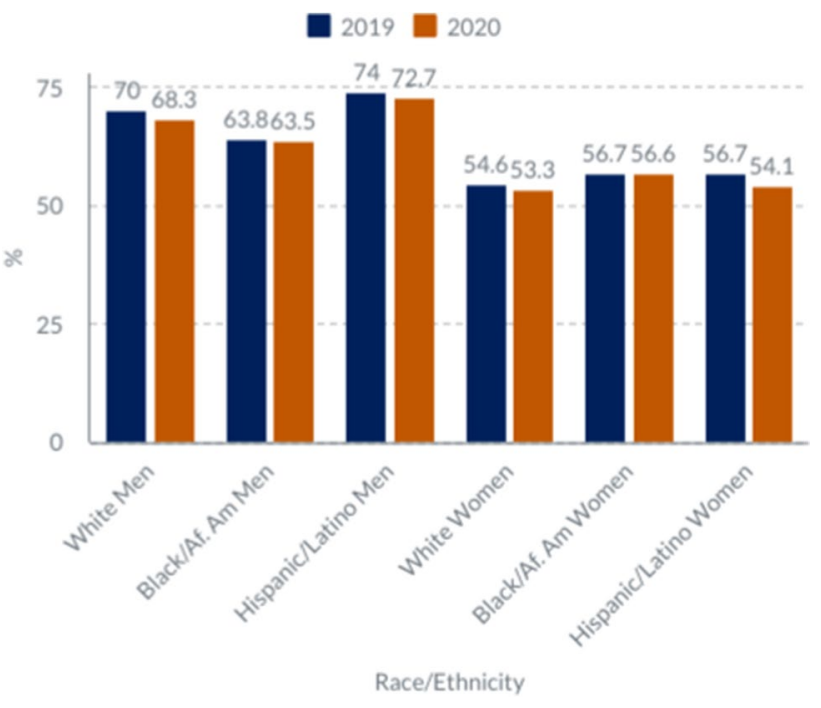

Fig. 1 Average labor force participation rate by race, ethnicity, and gender in 2019 and 2020 in California. Source: Authors constructions using data from US Bureau of Labor Statistics. BLS.gov

cases and $46 \%$ of all COVID-19 deaths in California. Whites represented $20 \%$ of COVID-19 cases and $32 \%$ of COVID-19 deaths.

Data from the BLS revealed stark racial and ethnic differences in labor market experiences in California. The average labor force participation rates (LFPR) for all racial and ethnic groups in California were below the national average in 2020. In particular, the average LFPR in 2020 for Latinos in California was $63.4 \%$, compared to $65.6 \%$ for Latinos across the USA. ${ }^{4}$ The average unemployment rate in 2020 was also higher in California than the national average (10.2\% in California versus $8.1 \%$ in the USA). The average unemployment rate in 2020 was $12.2 \%$ for African Americans, $11.7 \%$ for Latinos, and $9.9 \%$ for Whites in California.

We must recognize the intersectionality of race and ethnicity among women of color during the pandemic in California. Figure 1 shows the average LFPR by race, ethnicity, and gender in 2020 and 2019 in California. Latinas had the largest drop in participation in the labor force during the pandemic, where the average LFPR experienced a 2.6 percentage point decrease. Figure 2, which presents average unemployment rates by race, ethnicity, and gender in 2019 and 2020, shows that African American men had the highest rate in 2020 (13.4\%), followed by Latinas (12.6\%). The increase in California's average unemployment rate between 2019 and 2020 was the highest for Latinas, with an increase

\footnotetext{
${ }^{4}$ Data in this section from BLS comes from the Local Area Unemployment Statistics-Expanded Employment Status Demographic Data available here.
}

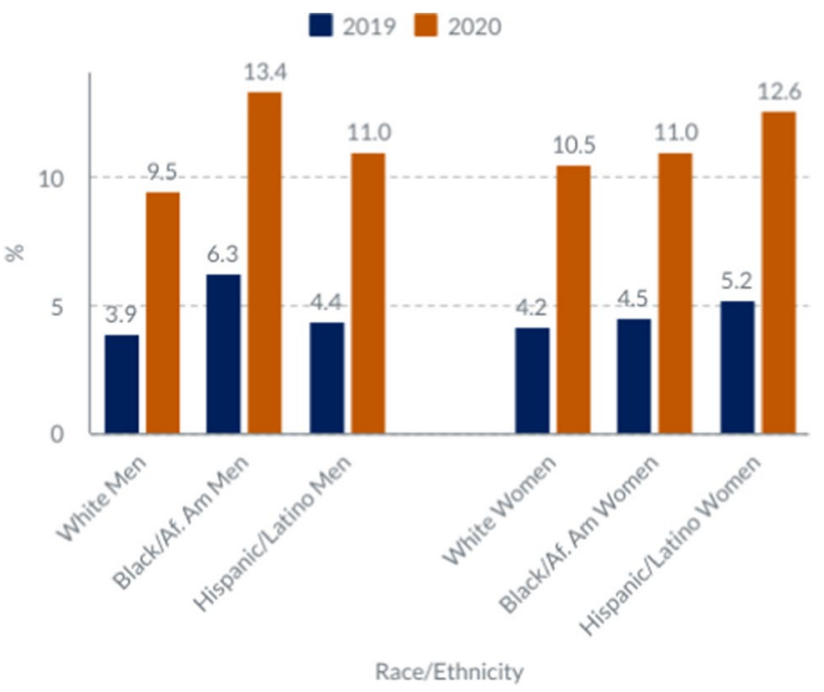

Fig. 2 Average unemployment rate by race, ethnicity and gender in 2019 and 2020 in California. Source: Authors constructions using data from US Bureau of Labor Statistics. BLS.gov

of 7.4 percentage points, followed by African American men, with an increase of 7.1 percentage points.

\section{Methodology}

\section{Data}

We recruited 84 Latino adults in California through the UAS Internet Panel, where participants answered surveys online via their mobile phone or computer. The UAS Internet Panel includes around 7400 households and is representative of the USA population aged 18 and older. Recruitment for the UAS uses postal records (address-based sampling). The purpose of the UAS is to provide researchers the opportunity to efficiently collect data about people's life experiences in relation to what they do, think, and feel over time (USC Dornsife Center for Economic and Social Research 2021).

The participants of this study were recruited among those who participated in the Mobile Financial Diary (MFD) project, which was conducted in 2018-2019 among a convenience sample of 134 LMI California Latino adults in the UAS. We stratified by age and income when recruiting for the MFD, and participants were asked to fill out monthly surveys about their finances and mental health for 6 months. The main goal of the MFD project was to collect data to better understand the challenges that California Latino adults face in managing their finances and the link between finances and stress. This pilot data was used for the design of a community-based mobile intervention on 
financial capability for Latino adults. ${ }^{5}$ Recruiting through the UAS for the MFD project was a good approach for this work given that it oversamples individuals in Los Angeles County and California and has a good representation of Latinos in the State. The data for the MFD was collected through an online monthly survey in the UAS from August 2018 to April $2019 .^{6}$

For this report, "before COVID-19" refers to data collected through the baseline survey for the MFD project from August to October 2018. We refer to the period "during COVID-19" to denote data collected in November of 2020 about personal experiences in October 2020. The discussion of quantitative and qualitative data analysis for the "during COVID-19" period in this report captures participant responses approximately 7 months after declaration of the initial state of emergency in California. ${ }^{7}$ Working with UAS to collect data via mobile phone and computer for this study was ideal given that COVID-19 cases were high and there were restrictions on gatherings that would have precluded us from collecting the data in person.

All 134 participants from the MFD were invited to participate for this study. We had a $63 \%$ response rate, with 84 participants responding to our survey that took place in November 2020 about the impact of COVID-19 on finances and stress. ${ }^{8}$ The November 2020 survey was similar to the one used for the MFD project. We used the same measures for financial well-being and behavior and mental health and added COVID-19 quantitative and qualitative questions. For the COVID-19 questions, we used quantitative measures previously developed by others, which we discuss in more detail next. Additionally, we had open-ended questions where participants entered their answers in a text field. These open-ended questions were similar to those in the MFD project about the relationship between finances and stress. We added open-ended questions that specifically addressed the impact of COVID-19 on finances and how that impacted stress (please refer to Appendix 1 in the online supplemental material for our survey questions).

\footnotetext{
${ }^{5}$ For information on Mind your Money mobile financial capability program funded by the Robert Wood Johnson Foundation, please go to project summary here: https://irlwebsite.wpengine.com/team/teamlos-angeles/.

${ }^{6}$ For accessing information on the MFD data, go to the UAS website (https://uasdata.usc.edu/index.php), and search in the surveys by topics for the financial literacy surveys.

7 Our project received approval by the Institutional Review Board at Pepperdine University (IRB protocol \#18-07-830).

${ }^{8}$ For more Information in our survey collected in November 2020, please go to UAS website. Our survey for this study is the UAS 317 survey.
}

\section{Measures}

For our quantitative analysis, we calculate scores to measure the financial health and well-being of our participants by using methodology from the Financial Health Network (FHN) and the Consumer Financial Protection Bureau (CFPB). The Financial Health Score combines eight indicators that measure financial health from four dimensions related to financial behavior: spending, saving, borrowing, and planning. This indicator gauges behaviors such as spending less than income and paying bills on time, having liquid or long savings, having a manageable debt or good credit score, and having appropriate insurance or planning ahead financially.

We also include in our analysis the CFPB Financial WellBeing Scale as it complements the Financial Health Score. The CFPB indicator is more widely used than the Financial Health Score and provides a holistic measure to assess individual perceptions of financial well-being so as to compare between individuals and across time. We also use several measures related to financial behavior from the Survey of Household and Economic Decisionmaking (SHED) conducted by the Board of Governors of the Federal Reserve System (2021). These measures, such as monthly income variation and emergency savings, were relevant in the context of COVID-19.

Since we are interested in studying the link between finances and stress, we also included in our survey several mental health measures. One measure previously used by the FHN asks whether the individual has experienced stress from finances, and whether financial stress had an impact on physical and mental health, work/school, or family. We also measured the anxiety and depression levels of our participants by using the generalized anxiety disorder (GAD-7) and the Patient Health Questionnaire (PHQ9). These two measures are commonly used and are valid and efficient tools. In a recent study by Donnelly and Farina (2021) on the impact of COVID-19 on mental health among households that experienced an income shock and the role of state policies, the PHQ-2 and GAD-2 are used. These measures are reduced versions of the measures we use. We also used the Pandemic Stress Index, which examines stress and behavioral changes that may have affected participants during the pandemic (Harkness et al. 2020). ${ }^{9}$

\section{Methods}

We took a mixed methods approach, where we analyzed data collected through quantitative measures of financial behavior

\footnotetext{
9 This indicator was developed by public health expert Audrey Harkness of the University of Miami in 2020. For more information on the PSI, visit the website of the Center for Excellence for Health Disparities Research.
} 
Table 1 Demographic and socio-economic characteristics of participants

\begin{tabular}{|c|c|c|c|c|c|c|c|c|}
\hline & \multicolumn{2}{|c|}{ Total sample } & \multicolumn{2}{|c|}{ Low income } & \multicolumn{2}{|c|}{ Medium income } & \multicolumn{2}{|c|}{ High income } \\
\hline & $\%$ & Count & $\%$ & Count & $\%$ & Count & $\%$ & Count \\
\hline Females & $69 \%$ & 58 & $78 \%$ & 31 & $61 \%$ & 22 & $63 \%$ & 5 \\
\hline Age (average) & 38 & & 37 & & 38 & & 39 & \\
\hline English language & $95 \%$ & 80 & $93 \%$ & 37 & $100 \%$ & 36 & $88 \%$ & 7 \\
\hline Foreign born & $27 \%$ & 23 & $28 \%$ & 11 & $28 \%$ & 10 & $25 \%$ & 2 \\
\hline Married or co-habitation & $76 \%$ & 52 & $57 \%$ & 20 & $95 \%$ & 26 & $96 \%$ & 6 \\
\hline One or more children & $51 \%$ & 43 & $58 \%$ & 23 & $42 \%$ & 15 & $63 \%$ & 5 \\
\hline \multicolumn{9}{|l|}{ Educational attainment } \\
\hline No high school diploma & $14 \%$ & 12 & $20 \%$ & 8 & $11 \%$ & 4 & $0 \%$ & 0 \\
\hline High school graduate & $11 \%$ & 8 & $20 \%$ & 8 & $3 \%$ & 1 & $0 \%$ & 0 \\
\hline Some college or assoc & $49 \%$ & 41 & $43 \%$ & 17 & $47 \%$ & 17 & $88 \%$ & 7 \\
\hline Bachelor's or higher & $26 \%$ & 22 & $17 \%$ & 7 & $39 \%$ & 14 & $12 \%$ & 1 \\
\hline Employed & $86 \%$ & 72 & $75 \%$ & 30 & $94 \%$ & 34 & $100 \%$ & 8 \\
\hline \multicolumn{9}{|l|}{ Employment sector } \\
\hline Government & $25 \%$ & 18 & $13 \%$ & 4 & $35 \%$ & 12 & $25 \%$ & 2 \\
\hline Private (for profit) sector & $50 \%$ & 36 & $50 \%$ & 15 & $44 \%$ & 15 & $75 \%$ & 6 \\
\hline Private (non-profit) sector & $18 \%$ & 13 & $30 \%$ & 9 & $12 \%$ & 4 & $0 \%$ & 0 \\
\hline Self-employed & $7 \%$ & 5 & $7 \%$ & 2 & $9 \%$ & 3 & $0 \%$ & 0 \\
\hline Health Insurance & $85 \%$ & 70 & $79 \%$ & 30 & $92 \%$ & 33 & $88 \%$ & 7 \\
\hline
\end{tabular}

Total sample includes 84 individuals $(\mathrm{N}=84)$. All variables but health insurance (health insurance, $\mathrm{n}=82$ ) have 84 observations. Groups are classified as followed: low income $(\$ 0-\$ 49,999) 48 \%$ of the sample $\left(\mathrm{n}_{\mathrm{LI}}=40\right)$, medium income $(\$ 50,000-\$ 99,999) 43 \%$ of the sample $\left(\mathrm{n}_{\mathrm{MI}}=36\right)$, high income $(\$ 100,000$ $\$ 149,999) 9 \%$ of the sample $\left(\mathrm{n}_{\mathrm{HI}}=8\right)$. Employed individuals include individuals on sick leave. The rest is unemployed (laid off or looking for work, 14\%). Data from this table comes from UAS myhousehold survey, which is collected when participants join the study and well-being and mental health, as well as open-ended questions on the link between finances and stress. For our discussion of quantitative measures, we compare participants' answers "before COVID-19" and "during COVID19". We take a descriptive approach, where we show statistics (percentages) on our measures of financial behavior and well-being and mental health-related variables. For several of our quantitative measures of interest that portray participants' experiences in relation to finances and stress, we conduct $t$ tests to evaluate any significant statistical differences in data before and during COVID-19. Given that we have a small sample size, we do not claim that our quantitative findings are representative of Latino adults in California. We only provide a descriptive analysis of the experience of a convenience sample of LMI Latinos in California.

For our qualitative data analysis, we used data about experiences during COVID-19 in October 2020 (collected in November 2020). We analyzed qualitative data taking a grounded theory approach (Glaser and Strauss 2012) and using the Rapid and Rigorous Qualitative Data Analysis (RADaR) technique developed by Watkins (2017). The RADaR technique provides a structured way to analyze qualitative data with a team-based approach. Data is coded in Excel and reduced systematically, allowing for themes to emerge.
Three researchers coded participant responses using a codebook and codes developed from a preliminary review of the qualitative data and previous research. After coding the qualitative data individually, researchers met to compare and contrast coded data and reach a consensus on the coding. After reaching a consensus on data coding, each researcher applied the RADaR technique to reduce text in several phases so that main themes emerge. The research team met to discuss the major themes observed in the data, and one team member was responsible for compiling the similarities and discrepancies on themes that emerged for each researcher. We include in our discussion of qualitative results the themes where there was a consensus for all team members.

Next, we discuss our quantitative and qualitative data results separately. Demographic characteristics of participants are discussed in the quantitative results section. Please refer to Appendix 1 (online supplemental material) for the survey we used for our data collection for personal experiences in October 2020. Appendix 2 (online supplemental material) includes the open-ended questions used to gather qualitative data and the codebook and codes used for coding the data. 
Table 2 Financial characteristics and behaviors before and after COVID-19

\begin{tabular}{|c|c|c|c|c|c|}
\hline & \multicolumn{2}{|c|}{$\begin{array}{l}\text { Before COVID- } \\
19\end{array}$} & \multicolumn{2}{|c|}{$\begin{array}{l}\text { During COVID- } \\
19\end{array}$} & \multirow[b]{2}{*}{ Diff } \\
\hline & $\%$ & Count & $\%$ & Count & \\
\hline \multicolumn{6}{|l|}{ Predict household monthly income } \\
\hline Every and most months & $76 \%$ & 64 & $79 \%$ & 66 & \multirow[t]{2}{*}{$3 \%$} \\
\hline About half the time, a few months, never able to predict & $24 \%$ & 20 & $21 \%$ & 18 & \\
\hline \multicolumn{6}{|l|}{ Household monthly income variation } \\
\hline Was roughly the same each month & $58 \%$ & 49 & $61 \%$ & 51 & \multirow[t]{2}{*}{$3 \%$} \\
\hline Occasionally and often varied from month to month & $42 \%$ & 35 & $39 \%$ & 33 & \\
\hline \multicolumn{6}{|l|}{ Rent or own home } \\
\hline Own (or buying) & $20 \%$ & 17 & $26 \%$ & 22 & \multirow[t]{3}{*}{$6 \%$} \\
\hline Rent & $69 \%$ & 58 & $65 \%$ & 55 & \\
\hline Live rent-free with relative/employer/friend and other & $10 \%$ & 9 & $8 \%$ & 7 & \\
\hline \multicolumn{6}{|l|}{ Household uses a budget } \\
\hline Yes & $45 \%$ & 38 & $37 \%$ & 31 & \multirow[t]{3}{*}{$-8 \%$} \\
\hline No & $46 \%$ & 39 & $55 \%$ & 46 & \\
\hline Don’t know & $8 \%$ & 7 & $7 \%$ & 6 & \\
\hline \multicolumn{6}{|l|}{ Household uses automatic transfers } \\
\hline Yes & $40 \%$ & 34 & $45 \%$ & 37 & \multirow[t]{3}{*}{$5 \%$} \\
\hline No & $46 \%$ & 39 & $49 \%$ & 41 & \\
\hline Don’t know & $13 \%$ & 11 & $6 \%$ & 5 & \\
\hline \multicolumn{6}{|l|}{ Household has a credit card } \\
\hline Yes & $79 \%$ & 66 & $84 \%$ & 70 & \multirow[t]{3}{*}{$5 \%$} \\
\hline No & $20 \%$ & 17 & $14 \%$ & 12 & \\
\hline Don’t know & $1 \%$ & 1 & $1 \%$ & 1 & \\
\hline
\end{tabular}

In the past 1216 months, how frequently have you carried an unpaid balance on one or more of your credit cards?^

Never carried an unpaid balance (always pay in full) $\quad 17 \% \quad \begin{array}{lllll}11 & 27 \% & 19 & 10 \%\end{array}$

Once, some, most or all of the time

$83 \% \quad 55 \quad 73 \% \quad 51$

In the past 1216 months, how frequently have you paid only the min. payment on one or more of your credit cards?^

Never

Once, some, most or all of the time

Have you set aside emergency or rainy-day funds

Yes

\begin{tabular}{lllll}
$21 \%$ & 14 & $30 \%$ & 21 & $9 \%$ \\
$79 \%$ & 52 & $70 \%$ & 49 & \\
& & & & \\
$27 \%$ & 23 & $42 \%$ & 35 & $15 \% *$ \\
$72 \%$ & 61 & $58 \%$ & 48 & \\
\hline
\end{tabular}

Total sample includes 84 individuals $(\mathrm{N}=84)$. ${ }^{\wedge}$ Denotes percentages calculated among those who have a credit card in the household. *Denotes statistical significant difference during COVID-19 (October 2020) in comparison to before COVID-19 (August-October 2018) for main category from a two sided $t$ test at the $5 \%$ level or lower

\section{Quantitative Analysis Results}

Table 1 summarizes the demographic and socio-economic characteristics of our participants, who were all California Latino adults. Among all participants, $69 \%$ were women, 95\% spoke English, 27\% were foreign born, $76 \%$ were married or cohabitating with a partner, $51 \%$ had one or more children, $85 \%$ had health insurance, and the average age of participants was 38 years old. In relation to labor market experiences, $86 \%$ of our participants were working; of those who were working, $68 \%$ worked in the private (for profit and non-profit) sector. Furthermore, most of our participants had at least some college or an associate's degree (75\%), and the average household income was between $\$ 40,000$ and $\$ 59,999$. Table 1 also shows our socio-demographic statistics calculated for three income groups in our sample: low income ( $\$ 0-\$ 49,999,48 \%$ of sample), medium income (\$50,000-\$99,999; 43\% of sample), and high income (\$100,000-\$149,999, 9\% of the sample). Low-income participants were less likely than others to be married or cohabitating with a partner, to be employed, or to have health 
Table 3 Financial health score and well-being scale before and during COVID-19

\begin{tabular}{|c|c|c|c|c|c|c|}
\hline & & \multicolumn{2}{|c|}{ Before COVID-19 } & \multicolumn{2}{|c|}{ During COVID-19 } & \multirow[b]{2}{*}{ Diff } \\
\hline & & $\%$ & Count & $\%$ & Count & \\
\hline \multirow{3}{*}{$\begin{array}{l}\text { Financial } \\
\text { health total } \\
\text { score, Avg }\end{array}$} & $\mathbf{5 3} \%$ & & $\mathbf{5 9} \%$ & & $6 \% *$ & \\
\hline & Vulnerable (0-39) \& coping (40-79) & $91 \%$ & 76 & $85 \%$ & 70 & \\
\hline & Healthy (80-100) & $9 \%$ & 8 & $15 \%$ & 12 & \\
\hline \multirow{3}{*}{$\begin{array}{l}\text { Financial } \\
\text { well-being } \\
\text { scale, Avg }\end{array}$} & $54 \%$ & & $\mathbf{5 0} \%$ & & $-4 \% *$ & \\
\hline & Low (very low, low, medium low) & $31 \%$ & 26 & $41 \%$ & 35 & \\
\hline & High (medium, high, very high) & $69 \%$ & 58 & $59 \%$ & 49 & \\
\hline
\end{tabular}

Total sample includes 84 individuals $(\mathrm{N}=84)$. *Denotes statistical significant difference during COVID-19 (October 2020) in comparison to before COVID-19 (August-October 2018) for main category from a two sided t-test at the 5\% level or lower. We calculate the Financial Health Score following the methodology used by the Financial Health Network (FHN). For more information on how the Financial Health Scores and sub-scores are calculated, please visit FHN (2021) website, Financial Health Score Methodology. Refer to Appendix 3, Table A1 for the survey questions used to calculate sub-scores. We calculate the Financial Well-being Score following the methodology used by the Consumer Financial Protection Bureau (CFPB). For more information, visit CFPB (2015) website, Measuring financial well-being: A guide to using the CFPB Financial Well-Being Scale. Refer to Appendix 3, Table A2 for the survey questions used to calculate sub-scores insurance. They also had lower levels of educational attainment in comparison to other income groups.

We discuss next our measures of financial behavior, wellbeing, mental health, and how they changed over time. We conducted two-sided $t$ tests to identify statistically significant changes and to identify changes for which differences were significant at the $5 \%$ level or less. Table 2 presents data on questions asked of the participants about their financial circumstances and behaviors before and during COVID-19. It shows that participants were more likely to predict their monthly income during the pandemic than before. There was also generally less monthly income variation for participants during the pandemic. Participants were more likely to own their home and less likely to rent during the pandemic. While there was an increase in the number of participants using automatic transfers and owning credit cards, fewer participants used a household budget during COVID-19. Regarding credit card use, there was an increase in those who never carried an unpaid balance and those who never made the minimum payment. There was a substantial increase in the number of participants who had set aside emergency funds (an increase of 15 percentage points). While there are differences in the percentages for most measures when comparing them before and during COVID-19, only the change in setting aside emergency funds is statistically significant at the 5\% level.

This is consistent with data from the SHED collected in 2019 and 2020. In their 2019 survey, 43\% of Latinos reported that they set aside emergency funds, and this number increased to $46 \%$ in 2020 . This is also consistent when comparing data for Whites, who experienced an increase from 61 to $63 \%$ in emergency saving between 2019 and 2020. It is important to note that the SHED numbers are for all Whites and Latinos, while our sample is composed only by LMI Latinos. The increase on emergency saving in our
LMI Latinos sample is much larger than what you observe in the SHED (15 percentage point difference in our sample in comparison to 3 percentage point difference in the SHED). ${ }^{10}$

Table 3 presents data on the questions about the Financial Health Score and Financial Well-Being Scale before and during the pandemic. The average for the Financial Health Score went from $53 \%$ before to $59 \%$ during the pandemic. This difference is statistically significant at the 5\% level. Using this score and the recommended grouping based on the score by the FHN, we observe that there was an increase of 6 points in the percentage of individuals in the "healthy" range, which represents a score in the 80-100 range. Interestingly, the average for the Financial Well-Being Scale decreased from $54 \%$ before to $50 \%$ during the pandemic. This difference is statistically significant at the $5 \%$ level as well. Using the CFPB recommended ranges, we observe that there was a decrease of 10 percentage points of those participants in the higher ranges on this scale. In our analysis, the Financial Health Score and Financial Well-Being Scale moved in different directions. One explanation for this difference is that while the Financial Health Score relates more closely to financial behavior, the Financial Well-Being Scale relates more to long-term financial circumstances and perceptions about financial well-being. We include the measures used in calculating each score with the summary statistics in the online supplemental material (Tables A1 and A2 in Appendix 3).

Table 4 presents data on questions about financial stress and mental health before and during the pandemic. During the pandemic, participants tended to experience less stress from finances than before, but the difference is not

\footnotetext{
10 The percentages noted here were calculated by the authors using unweighted raw data from the SHED.
} 
Table 4 Financial stress and health indicators before and during COVID-19

\begin{tabular}{|c|c|c|}
\hline $\begin{array}{l}\text { Before } \\
\text { COVID-19 }\end{array}$ & $\begin{array}{l}\text { During } \\
\text { COVID-19 }\end{array}$ & Diff \\
\hline Count & Count & \\
\hline
\end{tabular}

Stress from finances

$\begin{array}{lrllll}\begin{array}{l}\text { Some, moderate, and high } \\ \text { stress }\end{array} & 86 \% & 72 & 74 \% & 62 & -12 \% \\ \text { No stress } & 14 \% & 12 & 26 \% & 22 & \end{array}$

Financial stress impacted physical health^

$\begin{array}{llllll}\text { No impact } & 50 \% & 36 & 35 \% & 21 & -15 \% \\ \text { Some, moderate, and high } & 50 \% & 36 & 65 \% & 39 & \end{array}$
impact

Financial stress impacted mental health^

$\begin{array}{llllll}\text { No impact } & 33 \% & 24 & 23 \% & 14 & -10 \% \\ \begin{array}{c}\text { Some, moderate, and high } \\ \text { impact }\end{array} & 67 \% & 48 & 76 \% & 46 & \end{array}$

Financial stress impacted your family life ${ }^{\wedge}$

$\begin{array}{llllll}\text { No impact } & 24 \% & 17 & 32 \% & 19 & 8 \% \\ \begin{array}{l}\text { Some, moderate, and high } \\ \text { impact }\end{array} & 76 \% & 55 & 68 \% & 41 & \end{array}$

Financial stress impacted work or school performance ${ }^{\wedge}$

\begin{tabular}{|c|c|c|c|c|c|}
\hline No impact & $45 \%$ & 32 & $30 \%$ & 15 & $-15 \%$ \\
\hline $\begin{array}{l}\text { Some, moderate, and high } \\
\text { impact }\end{array}$ & $55 \%$ & 39 & $70 \%$ & 35 & \\
\hline \multicolumn{6}{|l|}{ nxiety } \\
\hline None and mild & $64 \%$ & 54 & $63 \%$ & 52 & \multirow[t]{3}{*}{$-1 \%$} \\
\hline Moderate and severe & $36 \%$ & 30 & $37 \%$ & 30 & \\
\hline epression & & & & & \\
\hline Minimal and mild depression & $63 \%$ & 53 & $77 \%$ & 63 & \multirow[t]{2}{*}{$14 \%$} \\
\hline $\begin{array}{l}\text { Moderate, moderately severe, } \\
\text { or severe depression }\end{array}$ & $37 \%$ & 31 & $23 \%$ & 19 & \\
\hline
\end{tabular}

Total sample includes 84 individuals $(\mathrm{N}=84)$. ${ }^{\wedge}$ Denotes percentages calculated among individuals who answered that they have experienced stress from finances (high, moderate, and some stress). * Denotes statistical significant difference during COVID-19 (October 2020) in comparison to before COVID-19 (August-October 2018) for main category from a two-sided $t$ test at the $5 \%$ level or lower. The measure of anxiety we use is the generalized anxiety disorder (GAD7) from Spitzer et al. (2006). For more information on this scale, refer to a Brief Measure for Assessing Generalized Anxiety Disorder. The measure of depression we use in our analysis is the Patient Health Questionnaire (PHQ9) from Lowe et al. (2004). For more information on this scale refer to Lowe et al. (2004) Measuring depression outcome with a brief self-report instrument: sensitivity to change of the Patient Health Questionnaire (PHQ-9)

statistically significant. We also show the percentage of participants who were experiencing financial stress and reported that it was impacting their physical health, mental health, work or school performance, and family life. Among those who experienced financial stress, there was an increase, albeit not a statistically significant one, in those who felt stress had an impact in all areas but family life.
When using the GAD-7 scale, we observe that the level of anxiety was relatively stable, with no significant difference between values before and during the pandemic. When using the PHQ9 scale, we find overall depression was lower during the pandemic than before, with the percentage reporting moderate, moderately severe, or severe depression, decreasing from 37 to $23 \%$, although this difference is not statistically significant.

Table 5 presents data on selected questions from the Pandemic Stress Index. Among our participants, 59\% did not experience financial hardship in October 2020. We observe that $21 \%$ of participants said that they lost a job, pay, or work hours due to the pandemic, while $12 \%$ said that their spouse or partner experienced one of the above. Most of our participants worked full time (89\%), and $97 \%$ worked $21 \mathrm{~h}$ or more per week. Most participants who were worried about friends, family, or partners were specifically worried about individuals who were in their local area (69\%). Most participants also said that COVID-19 impacted their day-today life extremely, very much, or much $(71 \%)$.

\section{Qualitative Analysis Results}

Participants in November 2020 were also asked openended questions about their overall financial well-being and stressors in October 2020. They were asked to share their personal experience about how COVID-19 impacted their household finances and stress. We discuss the main themes that emerged in relation to two categories: (1) impact of COVID-19 on work and finances and (2) major stressors during the pandemic.

\section{Category 1. Impact of COVID-19 on Work and Finances}

Participants' personal narratives made clear that they were significantly impacted financially. Of the 76 responses to our open-ended question about household finances, approximately $60 \%$ of participants reported financial impacts from the pandemic. We next discuss the themes that emerged in this category.

\section{Theme 1: State Closures Had a Negative Impact on Labor Market Experiences and Income}

Like much of the rest of the country, businesses in California were impacted by closures during the pandemic. Businesses that were not deemed to be essential were impacted more than those that were able to remain open with precautions. This meant that those who worked in restaurants, clubs, movie theaters, and in hospitality, among many others, were 
Table 5 Pandemic stress index (PSI)-related questions
$\%$

Count

\begin{tabular}{|c|c|c|}
\hline \multicolumn{3}{|l|}{ Experienced financial hardships } \\
\hline I did not experience financial hardship last month due to an event & $59 \%$ & 47 \\
\hline I lost a job & $10 \%$ & 8 \\
\hline I had my work hours and/or pay reduced & $11 \%$ & 9 \\
\hline My spouse/partner lost a job & $9 \%$ & 7 \\
\hline My spouse/partner had their work hours and/or pay reduced & $3 \%$ & 2 \\
\hline Unexpected medical care & $4 \%$ & 3 \\
\hline Other & $4 \%$ & 3 \\
\hline \multicolumn{3}{|l|}{ What is your labor force status? } \\
\hline Currently working, sick, or on leave & $83 \%$ & 67 \\
\hline Unemployed, layoff, and looking for work & $14 \%$ & 11 \\
\hline Other & $3 \%$ & 2 \\
\hline \multicolumn{3}{|l|}{ Work part time or full time } \\
\hline Full time & $89 \%$ & 59 \\
\hline Part time & $11 \%$ & 7 \\
\hline \multicolumn{3}{|l|}{ Hours work per week } \\
\hline More than $40 \mathrm{~h}$ & $30 \%$ & 25 \\
\hline $21-40 \mathrm{~h}$ & $67 \%$ & 56 \\
\hline $20 \mathrm{~h}$ or less & $2 \%$ & 2 \\
\hline \multicolumn{3}{|l|}{ Impact of COVID on day-to-day life } \\
\hline Not at all and a little & $27 \%$ & 22 \\
\hline Much, very much, extremely & $71 \%$ & 58 \\
\hline Decline to answer & $2 \%$ & 2 \\
\hline \multicolumn{3}{|l|}{ Who worried about } \\
\hline Locally & $69 \%$ & 37 \\
\hline In other parts of the USA & $6 \%$ & 3 \\
\hline Outside the USA & $9 \%$ & 5 \\
\hline Locally, in other parts of the USA & $7 \%$ & 4 \\
\hline Locally, in other parts of the USA, outside the USA & $4 \%$ & 2 \\
\hline Locally, outside the USA & $5 \%$ & 3 \\
\hline
\end{tabular}

Total sample includes 84 individuals $(\mathrm{N}=84)$. The Pandemic Stress Index (PSI) developed by Harkness et al. (2020) at the University of Miami. For more information on the PSI, visit the website of the Center for Excellence for Health Disparities Research. Selected set of questions out of work without a sense of when they would return to work.

A prominent theme in participant responses was having a significant loss of work hours or even of their place of employment. When businesses experienced complete and partial closures, many businesses were not able to keep their full staff due to only being able to provide limited services and had limited sales. This type of impact on businesses not only was a loss for the business owners, but losses also directly impacted business employees. One participant, who worked for their employer for a very long time and was forced to find alternative work, said, "My job of 14 y[ea] rs has been unable to reopen due to state restrictions and I have been forced to get a new job". Finding new work during a pandemic can also be challenging. The pandemic forced many people out of work when there were very few jobs available. One participant noted problems in the hospitality industry in particular, stating, "Me and my husband were bringing more than [\$]150,000 a year. We both stop working because we are in the hospitality business".

Participants who supplemented their pay with overtime, commission, and tips were also impacted financially. Businesses had to change in-person sales to online or curb-side pick-up procedures. The loss of commission in such transactions affected income for some participants. Narrative in the qualitative data showed that the loss of commission pay due to the change in sale modalities impacted participants' ability to gain extra income. One participant stated, "Due to the pandemic, I was not able to make sales, therefore I was only able to get by with my salary and no commission so that limited my income". Another participant stated, "I lost my 8 to 10 h overtime I had every two weeks". Those 8-10 h worked by the participant may have been important for the overall household income. A perspective that is also 
important to highlight is the experience of a business owner. Businesses also had to manage large losses, whether monetary or physical losses. As an example, a participant said "Due to the pandemic I lost a few clients, mainly from the restaurant community".

Many individuals were able to gain unemployment benefits, but some reported that these were not sufficient. One said, "Our household income has diminished a lot since I stopped working in March because EDD does not pay full salaries". ${ }^{11}$ This left participants with no choice but to use their savings or a line of credit to pay for necessities such as rent, food, and utilities. Another respondent said, "I am still on unemployment and it was difficult to make all the payments especially since the extra money got taken off[.] I am making less than my bills so I've had to start getting from my savings". Some households mentioned they lost partial income due to the loss of one contributing income. One participant said, "Due to the pandemic, my partner is no longer working. I am able to work my regular full-time job[,] but our savings has been needed to pay bills and rent".

\section{Theme 2: Women Are Affected the Most Due to Childcare}

Both women and men reported financial impacts from the pandemic. However, women reported having to stay home with their children or family members more often than males. COVID-19 caused many school and childcare center closures in California, which required families to host their children's education at home. For some families, this meant making accommodations with or even stopping work for some time to take care of their children. Those families who relied on schools to care for their children during hours of work saw their income decrease as their availably to work decreased.

Participants also noted in open-ended responses increased family care responsibilities for women. One woman said, "When the lockdown began[,] I was forced to stay tutoring my children who were unable to attend school while my partner worked. So for about 3 months we relied on his income plus our savings to cover some (not much) of our expenses". Another woman stated, "Due to the pandemic and schools being closed, I am no longer able to work because I need to care for my children. Our household income has diminished a lot since I stopped working in March". The increase in household and childcare responsibilities meant that earned income for females was disrupted more than that for their male counterparts.

\footnotetext{
11 Here, the participant is likely to refer to the Employment Development Department (EDD, 2021), which offers unemployment benefits, workforce investment, programs for labor market information, and state disability insurance. For more information on EDD, see its website at edd.ca.gov.
}

Many female participants reported also greater utility and food expenses during the pandemic. One participant commented that, "Everything is so expensive specially food". Another said, "[D]ue to COVID, I have had to spend much more in groceries. Everything is so much more expensive. Also[,] since we are home more, the utilities are higher". Participants associated these higher costs with more individuals working from home or just spending more time at home. Some respondents said children were not able to access all resources, such as regular nutrition, that were available to students at school.

\section{Theme 3: Essential Workers Experience Is Different}

Although many families reported that COVID-19 had a negative impact on finances, some participants did not report financial losses from the pandemic. Our qualitative data shows that some participants were able to continue to work their usual hours. Participants who had an essential job, such as healthcare workers or grocery store workers, were able to avoid some of the employment challenges that others experienced throughout the pandemic. In contrast to those participants who were at a loss, one participant who worked in healthcare was able to pick up hours to make up for any losses. A participant noted that "Since the pandemic, my finances have been the same as my work is classified essential. I was sent home one time but the CSL hours helped paid for $80 \mathrm{~h} .{ }^{12}$ Another participant who works as a tax preparer reported being able to work as usual, "My finances have not been affected by the pandemic. My job is considered essential and I also work as a tax preparer and I had more customers this year than the year before. I have not been infected with COVID-19 nor anyone in my immediate family".

Many of those who were able to maintain their employment reported working overtime hours to make up for any income losses. One participant said, "I have worked more hours in the month of October versus previous months in preparation for the holidays (retail). So we have been able to set aside additional money in case of another nationwide lockdown". Others reported being able to save money due to not having to drive and also by reducing non-essential spending like eating out and traveling. One respondent shared, "Due to my being at home and lack of driving, we were able to save some money on expenses such as gas and childcare". As expected, those participants who reported that they were able to work from home fared better than others who were out of work completely.

\footnotetext{
12 Here, the participant is likely to refer to the COVID-19 Supplemental Paid Sick Leave. For more, see the California Department of Industrial Relations website: https://www.dir.ca.gov/dlse/COVID 19Resources/FAQ-for-SPSL-2021.html.
} 


\section{Category 2: Major Stressors During COVID-19}

Given the many changes that came with the pandemic, many participants experienced stress. Our qualitative data shows that participants not only experienced stressors related to income, but also those related to other aspects of their lives. Below we discuss the major sources of stress reported by our participants.

\section{Theme 1: Financial Stress Due to Household Responsibilities and COVID-19 Exposure}

Respondents reported that household finances were the main source of stress. Participants noted increasing debts as a source of stress, and needing to pay for basic needs with credit cards, thereby increasing their personal debt. One participant shares, "Yes[,] I was stressed because I had a goal of getting out of debt and with corona I started using my credit cards again". Other participants reported that due to their loss of employment, they experienced stress from losing their steady income. One participant stated, "Last month things were difficult for us because of my reduced hours. I am trying to stay on track with all my monthly expenses". From the participants' responses to our open questions, we conclude that some respondents were able to budget before being affected by the pandemic, but once their work was affected, they did not have enough money left to budget.

Another important source of stress experienced by some participants was becoming the sole financial providers and taking on the responsibility of a household head. One participant shared, "Last month I was very stressed because I became the main source of income for my household. I have started a part time job in direct sales that I feel very positive about and will continue to pursue. I felt depressed because I feel like the mental state of my partner and I [is] declining".

Lastly, some participants expressed that exposure to COVID-19 caused stress because they had to quarantine at home and lost work hours. Unfortunately, some were even impacted by their co-workers' exposure. For example, those working in places where many employees tested positive for coronavirus saw their place of employment close and their income diminish. One respondent also expressed concern about sick hours: "This past October I had a little stress because two coworkers tested positive for Covid-19. Some staff were sent home for 14 days and had to use their sick hours. I was able to still come to work, I was cleared: I only have a few sick hours".

\section{Theme 2: Stress About Future Financial Stability and COVID-19-Related Uncertainty}

This pandemic has impacted California for over a year, without indication of when life might return to normal when this manuscript was written in March 2021. This ambiguity causes uncertainty about the future employment, resulting in more stress. A common stressor among respondents was the uncertainty about future work conditions and the duration of unemployment. Several participants also shared uncertainty around getting government assistance, which added stress to those needing this income. Those not knowing when their place of employment may re-open also did not know when they could return to their jobs. Many of these had to consider a different job or temporary substitution of income. One respondent said, "I have not been able to work since March due to losing my job with the pandemic. I am stressed out because I do not know when I will be able to find work again. I am worried about not being able to pay my bills when EDD cuts me off".

Even though some participants had returned to work, their families continued to struggle with expenses and unpaid bills. One participant discussed high stress resulting from uncertain work: "The stress level has been very high due to only one source of income coming in. I am stressed because I feel like not only are we using money we had saved for our future[,] but we are also set back in our timeline of future plans". The pandemic led some households to change their plans for the future. Some households that had been forward thinking were forced to think only of the present. High stress levels continued as the pandemic did. One respondent related, "I have not worked in the last 4 months due to losing my job. It has caused me severe stress because I haven't found work and not sure how long my savings will last or when I will find a job".

\section{Theme 3: Increase in Family-Related Stress Due to COVID-19}

Respondents faced an immense amount of pressure to support their families during uncertain times. Participants noted declines in their mental health because they were unable to socialize with family and friends and to engage in recreation activities such as going to the gym or going to public spaces like parks. Our qualitative data showed isolation was associated with depressed mood and high stress. Participants also reported that their children did not respond well to online learning and this was another source of stress: "We're all stuck at home and kids want to go to the park and vent. They want to hang out with their friends. [W]e're all so stressed with this pandemic". Children lost the ability to engage in school activities and sports and most peer socialization. Adults also lost their normal routines and had to adjust to working from home. One respondent summarized to the stress of distance learning and social distancing for children by saying, "Due to schools and several places being closed[,] my kids are not mentally where they should be[,] therefore making it stressful for me. I had to change my schedule at 
work and due to covid my work is slow and [we] have more days off but have more things to do".

Other participants reported stress due to not being able to see their extended family during the pandemic. Families and friends were not able to gather like they did before the start of the pandemic in March 2020. Holidays, birthdays, and other gatherings were no longer enjoyed as they once were due to social distancing. One participant commented on their experience, “.. I cannot function normally in social aspects and have not seen my extended family ever since pandemic started". Given the nature of the virus, many expressed fears about infecting loved ones with greater susceptibility to the disease. Other participants expressed stress over getting infected from other family members who contracted the disease. One said, "Stress was extreme. Both my Husband and Middle child caught COVID. Both recovered". As our qualitative data shows, it is evident that Latino families have been under high levels of stress resulting from school and business closures.

\section{Discussion}

Our qualitative data highlighted several areas of stress for respondents during the pandemic, but the scales we used to screen for possible mental health outcomes were seemingly unchanged. We hypothesize that the discrepancies between qualitative and quantitative analysis findings regarding stress, and the lack of quantitative measures capturing stress, might be due to the language used in the scales, related to mental health stigma, and a change in participant reference point. It is likely that these measures are unable to capture financial stress accurately.

The PHQ-9 scale that we used is typically a screen for mental disorders such as major depressive disorder, as defined by the Diagnostic and Statistical Manual of Mental Disorders (Spitzer et al. 1994; Kroenke et al. 2001). Validated scales such as the PHQ-9 can also capture potential mental health symptoms. Because we surveyed information related to stress, it was important to also learn about participants' mental health status and their propensity for stressinduced mental illness (Herbert 1997). Such information can help researchers in making policy recommendations. Because participants' depression scores did not increase significantly during COVID-19, it is possible that they did not experience a change in the problems listed since the 2018 baseline survey. This, however, does not rule out the possible experience of existing circumstantial stress.

Another measure we collected in our study is the GAD-7 scale, which is commonly used to screen for symptoms of generalized anxiety disorders (Spitzer et al. 2006). We also did not find any statistically significant changes for respondents from the "before" and "during" the pandemic. The
GAD-7 scale, like the depression scale, screens for potential anxiety disorders. Participants may not experience anxiety and circumstantial stress simultaneously. The APA differentiates stress from anxiety, by noting that anxiety "...is defined by persistent, excessive worries that don't go away even in the absence of the stressor" (APA 2020b). Participants may still be experiencing financial or other stress as the pandemic continues, meaning our assessment for symptoms of anxiety may be premature.

Mental health stigma also may have affected how respondents answered our questions and hence our findings. Latinos are among the least likely to engage with mental health services (Barrera and Longoria 2018). Socio-economic status, health insurance, and language are important barriers for Latinos seeking mental health services (Barrera and Longoria 2018). Cultural barriers, such as the negative perceptions of those who engage in mental health services, also exist (Barrera and Longoria 2018; Guarnaccia et al. 2005). Mental health professionals often lack understanding of cultural differences and fail to approach clients from different cultural backgrounds with an awareness of their perceptions of mental health (Dow 2011).

The survey questions from the PHQ-9 and GAD-7 that were included in this study included language which could be interpreted as stigmatized mental health language. This type of interpretation could have led fewer to report existing symptoms or experiences. For example, the GAD-7 and the PHQ-9 scale use the statements, "Not able to stop or control worrying" and "Feeling down, depressed, or hopeless" (Spitzer et al. 2006). How these statements are presented could have caused respondents to experience shame or embarrassment over their personal experience. These measures also use scaled response options such as "Minimal depression" versus "Mild depression", which can make it difficult for a participant to identify the best response that matches their experience. These scales should be more inclusive of the different types of experiences that individuals face, especially given the pandemic may have led to new stressors that respondents had not previously experienced related to financial uncertainty. The PHQ-9 and GAD-7 measures have never been used during a pandemic, and it is possible they are unable to capture the unique health- and economic-related stressors that individuals encountered during the pandemic.

Lastly, we note that participants' circumstances may have changed in other ways from 2018 to 2020 or from before to during the pandemic. Participants who felt stress in 2018 may have used that as their reference point for identifying future stress, and not reported any new changes as causing additional stress. For example, if a participant quantified living paycheck-to-paycheck as "very stressful" in 2018, and they lost their job and were not able to pay rent in 2020 , they may no longer see living paycheck-to-paycheck as "very 
stressful". By the time we surveyed participants 7 months into the pandemic, they may have seen enough changes in their personal circumstances to recalibrate how they perceived their financial situation.

We have identified several limitations from this study. One limitation stems from the small sample size of 84 participants. This may limit the generalizability of our work, but the sample still provides important insight on the economic and mental health impacts of the pandemic. An additional limitation was the inability to ask follow-up questions or for clarification of responses to the open-ended questions. Focus groups or individual follow-up interviews could have helped in constructing other themes. Lastly, the disconnect between the qualitative and quantitative data analyses prompted additional investigation about the scales and measures used to capture the participants' experiences during the pandemic for future research.

\section{Conclusion}

It is evident that Latino adults experienced stress due to the pandemic on their health, labor market experiences, and family circumstances in our study. Given that our qualitative data shows that state closures, and especially school closures, had led to high stress derived from family and financial circumstances among Latinos, we advise policymakers to work towards the safe reopening of schools. This may provide Latino families with the resources for economic and mental health well-being, both for children who can resume their progress in school and have access to other educational resources and for parents who can then better focus on the financial well-being of the household through their work. The safe reopening of schools in the Latino community in California will not only benefit Latino families economically, but also will reduce the high levels of stress they are experiencing during the pandemic.

Since our study shows that Latinos are under high levels of stress during the pandemic, we recommend a focus on providing mental health services for this population. Mental health professionals serving Latinos should pay special attention to economic and cultural barriers and stigmas that Latinos face in relation to requesting mental health services.

To address the mental health needs of the Latinos during COVID-19 in California, we also suggest cross-sector collaborations between community organizations, county departments of mental health, and school districts. Collaboration with school districts is crucial since schools are one of the most important institutions that provide support to underserved and immigrant populations. These collaborations could be helpful in devising effective interventions for wellness programs and eliminating the stigma associated with mental health services within the community. Schools may also offer a means to eliminate the stigma of mental health services for youths and their families. For example, a text message system provided by schools or community organizations for wellness check-ins may also offer a means to normalize and increase the use of mental health services. These cross-sector collaborations are imperative to provide the Latino communities with the resources and programs that can help them bounce back from the negative impacts of the pandemic.

Supplementary Information The online version contains supplementary material available at https://doi.org/10.1007/s41996-021-00087-0.

Acknowledgements We thank Pepperdine Office of the Provost and School of Public Policy Office of the Dean for providing funding for this project. Funding for data collected in 2018 and 2019 for the Mobile Financial Diary project, which is used in this analysis, was provided by the Federal Reserve of Minneapolis-Opportunity and Inclusive Growth Institute. This project relies on data from survey(s) administered by the Understanding America Study (UAS), which is maintained by the Center for Economic and Social Research (CESR) at the University of Southern California (USC). The content of this paper is solely the responsibility of the authors and does not necessarily represent the official views of Pepperdine University, Federal Reserve of Minneapolis, USC, or UAS.

\section{Declarations}

Conflict of Interest The authors declare no competing interests.

\section{References}

Acs G, Karpman M. Employment, income, and unemployment insurance during the COVID-19 pandemic. 2020. https://www.urban. org/research/publication/employment-income-and-unemployme nt-insurance-during-covid-19-pandemicofsubordinatedocument. Accessed 10 Jul 2021.

American Psychological Association. Stress in America 2020: a national mental health crisis. 2020a. https://www.apa.org/news/ press/releases/stress/2020/report-octoberofsubordinatedocument. Accessed 10 Jul 2021.

American Psychological Association. What's the difference between stress and anxiety? 2020b. http://www.apa.org/topics/stress/anxie ty-differenceofsubordinatedocument. Accessed on July 10, 2021.

Andrasfay T, Goldman N. Reductions in 2020 us life expectancy due to covid-19 and the disproportionate impact on the black and Latino populations. Proc Natl Acad Sci U S A. 2021;118(5). https://doi. org/10.1073/pnas.2014746118.

Azcue, X., D’Agostino, J., Gonzalez, O., Millán, I., Noel, N., Pérez, L., Pulido, A., Ramírez, M., Rivera, R. US Hispanic and Latino lives and livelihoods in the recovery from COVID-19. 2020. https:// www.mckinsey.com/industries/public-and-social-sector/our-insig hts/us-hispanic-and-latino-lives-and-livelihoods-in-the-recoveryfrom-covid-19-of-subordinate-document. Accessed 10 Jul 2021.

Bareket-Bojmel L, Shahar G, Margalit M. Covid-19-related economic anxiety is as high as health anxiety: findings from the USA, the UK, and Israel. Int J Cogn Ther. 2020. https://doi.org/10.1007/ s41811-020-00078-3.

Barrera I, Longoria D. Examining cultural mental health care barriers among Latinos. Clearvoz J. 2018;4:1. 
Blanco L, García-Pérez M, Mora M. Latinas and COVID19: unemployment, labor force participation, and family caretaking responsibilities. Hispanic Econ Outlook. 2020; 26-32.

Board of Governors of the Federal Reserve System. Survey of household and economic desicionmaking. 2021. https://www.federalres erve.gov/consumerscommunities/shed.htm of subordinate document. Accessed online $10 \mathrm{Jul} 2021$.

Bureau of Labor Statistics. Economic News Release February: Tables A, A-2, and A-3. 2021. https://www.bls.gov/news.release/empsit. toc.htm of subordinate document. Accessed online 10 Mar 2021.

CA.gov. COVID-19 cases dashboard. Tableau Software. 2021. https:// public.tableau.com/views/COVID-19CasesDashboard_15931 020425010/Cases?\%3Aembed $=\mathrm{y} \& \% 3$ AshowVizHome $=$ no of subordinate document. Accessed online 10 Mar 2021.

Center for Disease Control. COVID-19 hospitalization and death by race/ethnicity. 2021. https://www.cdc.gov/coronavirus/2019-ncov/ covid-data/investigations-discovery/hospitalization-death-by-raceethnicity.html of subordinate document. Accessed online $10 \mathrm{Mar}$ 2021.

Consumer Financial Protection Bureau. Measuring financial wellbeing: A guide to using the CFPB Financial Well-Being Scale. 2015. https://www.consumerfinance.gov/data-research/resea rch-reports/financial-well-being-scale/ of subordinate document. Accessed online $10 \mathrm{Jul} 2021$.

COVID19.CA. Tracking COVID-19 in California. 2021. https://covid 19.ca.gov/state-dashboard/ of subordinate document. Accessed online 10 Mar 2021.

Donnelly R, Farina MP. How do state policies shape experiences of household income shocks and mental health during the covid-19 pandemic? Soc Sci Med. 2021. https://doi.org/10.1016/j.socsc imed.2020.113557.

Dow H. Migrants' mental health perceptions and barriers to receiving mental health services. Home Health Care Manag Pract. 2011;23(3):176-85.

Dubay L, Aarons J, Brown KS, Kenney GM. How risk of exposure to the coronavirus at work varies by race and ethnicity and how to protect the health and well-being of workers and their families. 2020. https://www.urban.org/research/publication/how-risk-expos ure-coronavirus-work-varies-race-and-ethnicity-and-how-protecthealth-and-well-being-workers-and-their-families of subordinate document. Accessed online $10 \mathrm{Jul} 2021$.

Employment Development Department. EDD Services. 2021. https:// www.edd.ca.gov/about_edd/EDD_Services.htm of subordinate document. Accessed online $10 \mathrm{Jul} 2021$.

Financial Health Network. FinHealth score methodology. 2021. https:// finhealthnetwork.org/score/score-methodology/ of subordinate document. Accessed online $10 \mathrm{Jul} 2021$.

Glaser BG, Strauss AL. The discovery of grounded theory: strategies for qualitative research. New Brunswick: Aldine Transaction; 2012.

Gonzalez D, Karpman M, Kenney GM, Zuckerman S. Hispanic adults in families with noncitizens disproportionately feel the economic fallout from COVID-19. 2020. https://www.urban.org/research/ publication/hispanic-adults-families-noncitizens-disproportionat ely-feel-economic-fallout-covid-19 of subordinate document. Accessed online $10 \mathrm{Jul} 2021$.

Grooms J, Ortega A, Rubalcaba JA, Vargas E. Racial and ethnic disparities: essential workers, mental health, and the Coronavirus pandemic. Semantic Scholar. 2020;1-24.
Guarnaccia PJ, Martinez I, Acosta H. Mental health in the Hispanic immigrant community. J Immigrant Refugee Serv. 2005. https:// doi.org/10.1300/j191v03n01_02.

Harkness A, Behar-Zusman V, Safren SA. Understanding the impact of Covid-19 on Latino sexual minority men in a US HIV hot spot. Aids Behav. 2020.https://doi.org/10.1007/s10461-020-02862-w.

Herbert J. Fortnightly review: stress, the brain, and mental illness. BMJ. 1997. https://doi.org/10.1136/bmj.315.7107.530.

Karpman M, Zuckerman S, Kenney GM. Uneven recovery leaves many Hispanic, Black, and low-income adults struggling. 2020. https:// www.urban.org/research/publication/uneven-recovery-leavesmany-hispanic-black-and-low-income-adults-struggling of subordinate document. Accessed online $10 \mathrm{Jul} 2021$.

Kroenke K, Spitzer RL, Williams JBW. The PHQ-9: validity of a brief depression severity measure. J Gen Intern Med. 2001. https://doi. org/10.1046/j.1525-1497.2001.016009606.x.

Lopez M, Rainie L, Budiman. A financial and health impacts of COVID-19 vary widely by race and ethnicity. 2020. https://www. pewresearch.org/fact-tank/2020/05/05/financial-and-health-impac ts-of-covid-19-vary-widely-by-race-and-ethnicity/ of subordinate document. Accessed online $10 \mathrm{Jul} 2021$.

Löwe B, Kroenke K, Herzog W, Gräfe K. Measuring depression outcome with a brief self-report instrument: sensitivity to change of the Patient Health Questionnaire (PHQ-9). J Affect Disord. 2004. https://doi.org/10.1016/s0165-0327(03)00198-8.

New York Times. Coronavirus in the U.S.: latest map and case count. 2021. https://www.nytimes.com/interactive/2021/us/covid-cases. html of subordinate document. Accessed online 9 Jul 2021.

Pastor M, Segura G. No going back: together for an equitable and inclusive Los Angeles. 2020. https://dornsife.usc.edu/eri/no-goingback of subordinate document. Accessed online $10 \mathrm{Jul} 2021$.

Spitzer RL, Williams JB, Kroenke K, Linzer M, deGruy FV, Hahn SR, Brody D, Johnson JG. Utility of a new procedure for diagnosing mental disorders in primary care. The prime-md 1000 study. JAMA. 1994;272(22):1749-56.

Spitzer RL, Kroenke K, Williams JB, Löwe B. A brief measure for assessing generalized anxiety disorder. Arch Intern Med. 2006. https://doi.org/10.1001/archinte.166.10.1092.

Tadayon A. Quick guide: what California's now defunct color-coded county tracking system meant for schools. EdSource. 2021. https://edsource.org/2021/quick-guide-what-californias-colorcoded-county-tracking-system-means-for-schools/639357 of subordinate document. Accessed online $10 \mathrm{Jul} 2021$.

USC Dornsife Center for Economic and Social Research.Understanding America study: my household.. 2021. https://uasdata.usc.edu/ index.php of subordinate document. Accessed online $10 \mathrm{Jul} 2021$.

Vargas E, Sanchez GR. COVID-19 is having a devastating impact on the economic well-being of Latino families. J Econ Race Policy. 2020. https://doi.org/10.1007/s41996-020-00071-0.

Watkins DC. Rapid and rigorous qualitative data analysis: the "radar" technique for applied research. Int J Qual Methods. 2017. https:// doi.org/10.1177/1609406917712131.

Zamarro G, Prados MJ. Gender differences in couples' division of childcare, work and mental health during COVID-19. Rev Econ Household. 2021. https://doi.org/10.1007/s11150-020-09534-7.

Publisher's Note Springer Nature remains neutral with regard to jurisdictional claims in published maps and institutional affiliations. 